\title{
14 SOCIAL INCLUSION AND THE SHIFTING ROLE OF TECHNOLOGY: Is Age the New Gender in Mobile Access?
}

\author{
Carl Adams \\ Tineke Fitch \\ University of Portsmouth \\ Portsmouth, U.K.
}

\begin{abstract}
Information and communication technologies (ICT) are at the heart of government social inclusion policy. However, the "digital divide" remains and social inclusion and technology are closely linked: Not having access to technology is often seen both as part of the inclusioniexclusion problem and part of the solution by enabling access to information resources through different channels. Yet, we argue that by using technology to address an inclusion/exclusion problem, it will also result in moving the problem from one area to another. The arguments in this paper have been informed by two empirical studies around a ubiquitous technology, the mobile phone. One study is primarily based on the 18 to 25 year old age groups; the other mostly on retired people. The studies show clear differences between age groups and gender in adoption and use of the mobile telephone.

Social inclusion is multifaceted; it is not an either/or measure and many attributes are subjective and depend on context. Social inclusion for mobile access is also closely linked to deeply embedded structures within society, such as those traditionally associated with gender. Technology may be changing these structures; indeed, age may be the new gender. The family or social unit may also be a useful entity to consider in the exclusion debate. Technology is being used to address social exclusion; however, we suggest that while some leveling may result, there may also be different social exclusion fronts emerging.
\end{abstract}

\section{INCLUSION AND TECHNOLOGY}

This paper examines social inclusion and exclusion and the role of technology through a ubiquitous technology: the mobile phone. The aim of the paper is to see how

Please use the following format when citing this chapter:

Adams, C., and Fitch, T., 2006, in IFIP International Federation for Information Processing, Volume 208, Social Inclusion: Societal and Organizational Implications for Information Systems, eds. Trauth, E., Howcroft, D., Butler, T., Fitzgerald, B., DeGross, J., (Boston: Springer), pp. 203-215. 
technology impacts inclusion activity in technology dominated societies. The paper draws upon some government practice and thinking in addressing exclusion within the digital divide. Two empirical studies on mobile phone use and adoption are used and related to current thinking about social exclusion. There are many definitions of the terms social inclusion and exclusion (Britton and Casebourne n.d.) and the terms are used differently in different contexts, although the Scottish government's definition brings out most of the common attributes:

Social inclusion is about reducing inequalities between the least advantaged groups and communities and the rest of society by closing the opportunity gap and ensuring that support reaches those who need it most.'

Social inclusion is about reducing the inequalities between differently advantaged groups, particularly when providing support and services. Social inclusion and exclusion have been very topical areas of concern in the United States, particularly during the Clinton years, as well as in the Europen Union and many other countries in recent years (Warschauer 2002). This has resulted in government policies aimed at reducing inequalities between the least advantaged groups and the rest of society. Much of this policy has been focused on closing the opportunity gap by giving fair access to resources and usually follows altruistic motives and rhetoric.

The idea of "social inclusion" is now the central legitimating concept of social policy in Europe and elsewhere. There is a general agreement that inclusion is a good thing, and that exclusion is a bad thing, both because it is unfair, and because it damages social cohesion. There is also very little clarity about what inclusion or exclusion actually mean, and indeed to some extent the unifying function of these terms depends on that lack of clarity (Levitas 2003, p. 1).

Information and communication technologies (ICTs) are at the heart of government social inclusion policy, which is unsurprising, as increasing use of technology has created a "digital divide." For instance, one of the flagship inclusion projects for the UK government is "Inclusion through Innovation," which focuses on how ICT can be used to generate equality of opportunity for disadvantaged groups in society.

The Social Exclusion Unit project, "Inclusion through Innovation," is focused on identifying the specific needs of the most disadvantaged groups and exploring how Information and Communication Technologies (ICT) can help to address these needs, both through improved service delivery and through empowerment of service users. ${ }^{2}$

'This definition of social inclusion is taken from Scottish Executive People \& Society (http://www.scotland.gov.uk/Topics/People/Social-Inchusion).

${ }^{2}$ From the Social Exclusion Unit "Inclusion through Innovation" Project website (http://www.socialexclusionunit.gov.uk/). 
In this project, like many other government based projects, technology is seen as one of the main answers to address inequalities of opportunity. This is particularly so with the so-called digital divide, between those who can and cannot make use of ICT in its full glory. This view is supported with fairly compelling evidence.

The Social Exclusion Unit has reviewed a large amount of evidence which appears to support the view that ICT can potentially help improve outcomes for people across a number of key areas including:

- Addressing educational underachievement:

- Addressing worklessness

- Addressing social isolation ${ }^{3}$

Social inclusion is key to government social policy and ICT is used as an indicator of the level of exclusion and a facilitator to improve access to services. For instance, one area that is at the forefront of such ICT based social inclusion policy is healthcare provision. Healthcare illustrates many of the challenges of providing inclusion discussed earlier, but also highlights other aspects, notably that there is an inherent funding versus provision dilemma and that it is usually very political. As Fitch and Adams (2006, p. 6) note,

Healthcare is a highly politicized arena.... The larger political dimension brings in other challenges. When there is a change of governing political party then there is a political need for the new party to deliver on electoral promises before the next round of elections. This equally applies to changes in political or executive healthcare posts, with new incumbents wishing a "return" on their investment, with improvements within tight timeframes.

In the UK, technology is seen as one of the main tools to achieve equity of healthcare provision as well as to keep down the healthcare provision costs. For instance, in "Delivering the NHS Plan" (DoH 2002) and the influential Wanless report (Wanless 2002), investment in information technology is identified as a fundamental route to providing and improving service provision and keeping costs down. After the Wanless report, a new IT director for the National Health Service, with a $£ 12$ billion budget, was appointed in September 2002 to implement the NHS information strategy and achieve the "effective use of IT" promoted in the report. As noted in the Wanless report,

Without a major advance in the effective use of ICT...the health service will find it increasingly difficult to deliver the efficient, high quality service which the public will demand. This is a major priority which will have a crucial impact on the health service over future years (Wanless 2002, p. 5).

These political and funding dimensions to healthcare systems in the UK have also been noted by the European Observatory on Health Care Systems.

${ }^{3}$ From Age Concern's comments on the Social Exclusion Unit (http://www.ageconcern.org.uk/ageconcern/). 
Health policy is currently the most high profile item on the political agenda. Debate and public policy is focusing on both the finance and provision of healthcare (EOHCS 2002, p. 113)

So technology plays a key role in many government social policy as well as political programs. Technology is seen as one of the keys to achieving inclusion as well as reducing the costs of such service provisions and gaining and keeping the political favor of the electorate.

However, technology by itself cannot address the exclusion problem, a theme that Mark Warschauer demonstrates through case study vignettes.

Each of the programs described in the preceding vignettes was motivated by a sincere attempt to improve people's lives through ICT. But each program ran into unexpected difficulties that hindered the results. Of course any ICT project is complicated, and none can be expected to run smoothly. But the problems with these projects were neither isolated, nor random. Rather, these same types of problems occur again and again in technology projects around the world, which too often focus on providing hardware and software and pay insufficient attention to the human and social systems that must also change for technology to make a difference (Warschauer 2002, p. 7).

Access to ICT is embedded in a complex array of factors encompassing physical, digital, human, and social resources and relationships. Content and language, literacy and education, and community and institutional structures must all be taken into account if meaningful access to new technologies is to be provided (Warshauer 2002, p. 7).

Social exclusion issues are politically charged and intrinsically linked to technology, with investment in technology often being used as a means to increase inclusive provision of services. But achieving inclusion through technology is likely to involve more than just providing the hardware and software; an understanding is also needed of the wider human aspects and social environment (Warschauer 2003).

The next section will examine two research studies into the use and adoption of one of the most ubiquitous technologies used in the Western world, the mobile phone. The studies cover two different age groups, young adults and retired people, and comparisons are made between the use patterns of both groups.

\section{RESEARCH STUDIES: MOBILE TECHNOLOGIES}

Several business and social commentators argue that the future is mobile (e.g., Economist 2002; Thomas 2003) with many information services, business practices and social activities being based around increasingly sophisticated mobile devices. This view was extolled by British Telecom's marketing in the late 1990s, proclaiming that geography is history, and reinforced with more recent, similar marketing by telecommunications and computer companies with the clear expectation that technology-enabled 
mobile working and living is becoming a significant aspect of society. People have the ability to work, communicate and socialize independently of geographical location. Mobile phone technologies play an integral part in this technology-enabled mobile world, providing people with the ability to communicate and access information seemingly wherever they are. In addition, mobile phones are truly pervasive, with adoption levels of 70 percent in many countries and even over 100 percent for some user groups (i.e., some groups have more than one mobile phone). However, according to Warschauer's (2002) perspective, just "having" a mobile phone does not necessarily guarantee the mobile phone owner the full potential of communication and information access. Indeed, the pervasiveness of mobile phones provides a good base to examine the wider human aspects and social environment identified by Warschauer.

Two empirical works are used to examine very different groups of mobile phone users. One of the studies, focusing on young adults' use of mobile phones, has been running for 5 years and a fuller description of this study can be found in Adams et al (2003) and Adams and Millard (2003). The other study, focusing on retired users of mobile phones, had a preliminary report in Jeffcote et al (2003) and the full report is awaiting publication. Individually, each of these studies raised some interesting aspects of mobile phone use in each of the user groups. However, combining and comparing the studies brings out some pronounced inclusion and exclusion attributes of using mobile technologies and the services to which they give access. Both studies investigated how people used their mobile phones, how attached people are to them, and a range of related issues around the use of mobile phones.

The young adults study was based on a questionnaire survey given to university students, and included responses for one of the years from three different universities in different countries. The other years were limited to one university in the UK. The number of responses now exceeds 1,200. Focus groups of students have also been used to confirm the questionnaire responses and to get a deeper understanding of the issues surrounding mobile phone use for the young adult student group.

The other study was aimed at addressing a lack of research into mobile use by older age groups at the time. The study revolved around a qualitative survey of a sample from the general public conducted through the Mass-Observation Archive (MOA) at the University of Sussex in the UK. The survey (called a "directive" within the MOA), was sent out to a self-selecting panel of people across the UK. The panel is biased toward the older population with the average age of panel members being over 60 years old. The panel also contains gender biases with approximately two-thirds of the panel members being female. However, the panel does represent people from a wide selection of socio-economic backgrounds and is likely to provide a good window into every day contemporary life (Sheridan 1996). For the purpose of the study, it provided a rare window into mobile phone use and issues for the older community. The study consisted of a directive (survey) on mobile phone use in 2002 and a comparison with a previous directive in 1996 on (landline) phone use. The 2002 directive contained open-ended questions, or themes, that panel members could write about. The MOA administers the distribution, collection, and coding of the directives and associated responses. The confidentiality of each respondent is ensured by a coding system that enables researchers to identify the gender, occupation, town (or approximate location), and age of respondents, without actually giving information that could identify a respondent. The average age of respondents for the 2002 directive was 64 , with over 60 percent of respondents 
being retired. The number of panel members that responded was 193 (140 female, 53 male), and represented 56 percent of the panel population. The responses provided a rich set of data, ranging from a few paragraphs to several pages of unstructured prose. Mobile phone ownership among the panel members was over 60 percent, which compared with an ICM poll in 2002, giving mobile phone ownership of the $60+$ age group of about 50 percent.

Comparing the two different studies has its own challenges, given that they involved different methods and different types of responses. This will be discussed later in the paper. The comparisons below cover some of the main issues brought out by either one group or by both groups of responses.

\subsection{Attachment to Mobile Phones}

The study of young adults asked explicit questions about how attached people were to their mobile phones, whereas the questions to the retired age group were more open ended. However, attachment to mobile phones was one of the most often identified themes for the older age group responses.

The young adults as a group had more attachment to their mobile phones than the older age group. Indeed, the young adult responses indicate a very close attachment, with respondents taking their phones just about everywhere, the majority of them willing to return home even when running late to collect their phone if they had inadvertently left home without it.

Interestingly, the responses from the older age groups indicated some also had a very close attachment to their mobile phones, although the responses were split roughly in half between those that did and those that did not. The attachment to mobile phones for the older generation seemed to be based around a need to be in contact with a specific group (such as close family), whereas the attachment for the younger age group seemed to be more complex.

\subsection{Gender and Generation Issues}

Some responses brought out gender differences; for instance, both studies investigated reasons for having a mobile phone. For the young adults being able to be contacted and to be able to contact other people were the two highest ranked. However, the locus of control (i.e., being able to be contacted and being able to contact) seems to have been different for many people, since they placed one attribute higher than the other. For some people, it is more important to have the ability to be contacted than to be able to contact other people; for others it is the other way round. There was a slight gender bias here with males rating more highly the ability to contact than be contacted, while it was the other way round for females. Interestingly, this gender difference was more pronounced in different groups of young adults at different universities, possibly indicating a wider set of influences at play.

For the older age group of respondents, there were some gender differences but these were more complex and were muddled with aspects of partner and offspring influences. There were paternal and reverse parental elements in the responses, where one of the partners (usually the male) "viewed" a need for the other partner to be either 
contactable or have the ability to contact. The responses seemed to imply something similar originating from the children of the respondents, for instance where the respondents retell a story of their son/daughter buying them a mobile so that they can call or be called by the son/daughter. The generation issue of purchasing and exerting influences on use (i.e., $b y$ the offspring for the parents) seemed to be very similar to the power issues in engendered technologies. There were several examples of the respondents' children not only influencing the purchase of the mobile phone (i.e., buying, giving, choosing) but also influencing how and when it is used (i.e., training, showing how to use, being the main initiator of calls or texts). Also, having the ability not to be contacted was a very strong issue for many of the older age group respondents, both male and female.

\subsection{Mobile Phones, Safety, and Wider Use}

For the young adult respondents, a substantial proportion indicated that the mobile phone makes them feel safe, such as when driving a car or to a lesser extent when walking. The questionnaire also asked for areas of concern regarding using mobile phones. "Theft of mobile phones" had a high response; however, "loss of personal information" had a slightly higher response. The loss of the phone itself seemed to be less important than the loss of the phone's personalized functions, such as personal data.

These results seem to imply that the mobile phone is more than a communication device: the mobile phone is fulfilling support functions contributing to perception of being safe, keeping and providing personal information, as well as providing a contacting and contactable function. The respondents seem to have a very close attachment and relationship with their mobile phones. The relationship seems to be complex (Adams and Millard 2003, p. 5).

Correspondingly for the older age group of respondents, safety also played an important role, although it was usually as a just-in-case rather than a continual feel safe function. For instance, older respondents would typically retell a tale of how they bought (or were bought) a mobile phone after an event such as breaking down in a car, but also they would as likely describe keeping the mobile in the car and not even have it switched on. The concern of any loss, if the respondents raised it, was mostly just focusing on the loss of the phone and not of any data.

This seems to highlight some very clear differences in use emerging from the two studies: the younger age group seem to be using the mobile phone for a variety of functions, much of which revolves around socializing and a range of access to information and services via their mobiles; the older age group seem to be using the mobile phone "just as a phone" and not utilizing the extra functionality and access to services via their mobiles. It was clear that the population of older respondents were very diverse in their attitudes and the ways they used the technology. There were stark contrasts from attitudes of "hating" the devices to "can't live without" (although these were fewer), or from constant, everyday use to being locked away for most of the time. There were also some gender and age differences in how people perceived and used the mobile phones (e.g., duration and type of calls, how they viewed other people using mobile phones). 


\section{REVISITING INCLUSION AND EXCLUSION AND MOBILE USE}

The studies bring out some differences of use and access to mobile phones for the two groups. For the older age group, relatively few respondents were using SMS and the more sophisticated functions of mobile phones, even when they had had a mobile for several years. Indeed, many kept their mobile phones switched off and preferred using landline phones for most calls. Attitudes toward mobile phones varied considerably, ranging from people hating the mobile phones to people saying they couldn't live without them. For many people there was a grudging acceptance and tolerance of mobile phones, with many identifying benefits such as security or emergency use. In contrast, the younger age group were far more embracing of functions and attitudes toward the use of the mobile phones. Some quite sophisticated use was identified where the mobile was an integral part in the socializing, studying, working, and general living. There also seemed to be some parent-child role reversal as the sons and daughters were buying phones for their parents, which is different from the younger age groups, where the parents buy phones for their children. The same seems to be true with using the more sophisticated functionality of the mobile devices: where in the past it may have been the parents showing their children how to use something, with mobiles it is often the children showing the parents.

The comparisons of mobile phone use for the young adults and the older generation seems to confirm Warschauer's (2002) view that achieving inclusion through technology is likely to involve more than just providing the hardware and software. An understanding is also needed of other factors such as the wider human aspects and the social environment. Below are some of the factors that seem relevant from comparing the two different age groups' use of mobile phones.

\subsection{Inclusion-Exclusion Is Relative}

One could take the meaning of relative to be both meaning "family/social relations" and "relative to context." For the older age group, accessing and using the mobile technology was influenced, or even directed, by other family members, notably children. The family or social unit, where it exists, may therefore be a useful entity to consider in the inclusion-exclusion debate.

The relative to context meaning is drawn from the very different use patterns, needs, and context for the different groups. For the young adult age group, the mobile was fulfilling many needs (e.g., communication, security, socializing, playing, information), whereas the older group had a different, more limited set of needs. The younger group were using the mobile technology to explore, define, and refine their needs. The older age groups already had well defined needs, and were mostly fulfilling those with their existing activities. There are clear parallels for technology access on national and international scales; for instance, access to technology within the majority of the technologically developed West is likely to be considerably different from access in other parts of the world, since they would have different needs and different contexts with which to contend. Inclusions and exclusions have to be considered within the 
context of the environment, whether it is on a national scale, in the work environment, or even in the home environment.

\subsection{Inclusion-Exclusion of Access is Subjective}

Although both studies indicated people with both high and low levels of access to the technology, the access was fairly granular. The younger age group had higher levels of access and a wider, more sophisticated level of use. There was also quite a range in use patterns. The range and granularity of use was considerable in the older age group as well. Deciding whether and who had inclusive or exclusive access was not clear-cut. Further, as Levitas (2003) identified, there is little clarity about what inclusion or exclusion actually mean. One could argue that exclusion and inclusion are subjective terms and could be considered on a sliding scale rather than on a fixed metric; that is, people toward the "inclusive" end of the scale have greater access to resources than those toward the "exclusive" end.

\subsection{Technologies Moves the Inclusion-Exclusion Barriers}

There seems to be a pattern of changing access needs, barriers, and practices emerging from the different levels of use for the respondents in both studies. For instance, at a basic level, barriers to inclusive use could relate to having access to a mobile phone and some basic training on how to use it. For less basic use, barriers to inclusion could be having the right type of phone with access to the Internet or signal coverage in all the areas the users want. For more sophisticated and enabling use, barriers to inclusion could include access to even more sophisticated information or location-aware services and infrastructure. Cost issues also seem interlinked here. As the technology evolves, the initially expensive sophisticated technology used by the "first to market users" invariably evolves to be the basic technology used by other groups. This was demonstrated in the older age groups respondents, a significant proportion of which had hand-me-down phones from their children or other relatives.

The needs and the barriers for exclusion move as the technology evolves. Technology changes things. This concept is not new. For instance, Hebert (1998, p. 69 ), studying healthcare provision in five community hospitals, noted

results suggest that, for specific tasks, IT increased efficiency and productivity - a single employee was able to complete more tasks. However, this produced other consequences not predicted. Participants noted this change did not "free up time" to spend with patients, but meant there were potentially more opportunities to provide services and more tasks to complete.

So in Hebert's study, technology that was meant to increase quality of service to patients often resulted in less frequent and shorter contact between staff and patients, as staff time was increasingly taken up with computer-oriented tasks. Issues and barriers to providing equity of patient service moved from "things healthcare staff did with patients" to "things healthcare staff did with technology." 
When considering inclusion issues, then, some understanding is needed of the intricate and evolving role of technology. Technology will help define and move the barriers to inclusion as it evolves.

\section{TECHNOLOGY CHANGES STRUCTURES: IS AGE THE NEW GENDER?}

The idea that technology defines and moves barriers has further meaning when we consider the earlier age/gender observation and discussion. There is a link between gender and technology use. For instance, in the use of Internet technologies, differences have been noted, some arguably related to traditional gender roles and barriers (e.g., Turkle 1995; Wallace 1999). In addition, women communicate differently and can be more self-deprecating and less confident than men (Tannen 1990).

However, the gender literature raises several more fundamental inclusion issues relating to access to technology, work, wealth, and standing (e.g., Rantalaiho and Heiskanen 1997a, 1997b; Wajcman 1991). Work and corresponding societal structures and practices are geared to favor men over women. Technology plays a part in facilitating and perpetuating gender work and social role differences by providing both channels and barriers to access.

Males may be more involved in "higher" activities of designing and making technology while females may be more involved in "lower" activities of using the technologies. Generally there is a bias toward exerting influences on working and social practice by males for females. This is likely to be engrained in the deeply rooted structures. As Rantalaiho and Heiskanen (1997b, p. 191) note,

Quite often "gendered" means the common hierarchical difference between men and women, between the masculine and the feminine, with men and masculinity in the dominant position. The difference is quite strong in the working life all over the world, and also where gender equality is an acknowledged ideology.

They also note, however, that the differences can be subtle and unintentional.

Gendered hierarchies are not always visible or audible at the workplace level. It is rather rare in the present Western part of the globe that a researcher can point to open and conscious discrimination of women. Instead, the prevailing construction of women's hierarchically lower positions is a delicate practice in which women and men mostly do not intentionally indulge. Gender is constructed at the workplace in the daily work process and it is involved in solutions about how to organize the work. Some jobs and tasks almost unnoticeably become defined as feminine and others as masculine (p. 191).

The earlier discussion shows a younger generation embracing, adopting, and engrossing themselves in the technology and using this "expertise" to direct and inform 
the older generation (of both sexes) in the use of such technologies. There seems to be embedded hierarchical difference between the young and the old, not only in use but in design (i.e., with mobile technology designed by and for the young and not the old). In using the more sophisticated mobile technology, there seem to be well-defined hierarchical structures emerging, with many activities becoming firmly the realm of the young.

Perhaps we are seeing some changes in the deeply embedded gender role structures here, with the younger generation taking on what used to be the confident, masculine roles and older generation taking on the less confident, feminine roles. With a continually changing and evolving technology, such as mobiles, the older less confident may become more excluded from the facilities the technology offers.

\section{CONCLUSION AND AREAS FOR FURTHER RESEARCH}

The paper has argued that ICTs are at the heart of government social inclusion policy but that social exclusion and technology are inextricably linked. Technology, and access to it, is often seen as part of the exclusion problem, as well as part of the solution to enable access to information resources.

Two empirical studies, one looking at the use of mobile technologies by a 18 to 25 year old age group and the other of mostly retired users, have been used to examine inclusion and exclusion issues. There are limitations with this research. The studies were different, involving different methods and different types of responses. In addition, the focus of each study was not on inclusion or exclusion, and it was only once both studies were completed and the results combined that inclusion and exclusion emerged as issues. Combining the results and responses of both studies has proved challenging. There have been some subjective decisions over which data to use and how to combine elements in one data set with a different data set. Clearly further research is needed to examine the age and ICT dimension of inclusion. Such research needs to follow a consistent focus and methodological approach. The target sample would need to be more fully representative of the population, such as involving different economic groups and more delineated groups, possibly involving younger age groups. The study will need a ubiquitous technology, such as a mobile phone, to provide a common focus for investigation.

Limitations aside, several themes derive from examining these two sets of respondents. Using technology shifts the inclusion and exclusion problem landscape. Social inclusion is multifaceted and not a simple either/or situation, and should be considered rather as a subjective sliding scale dependent on context rather than an absolute. The family or social unit where it exists may also be a useful entity to consider in the exclusion debate. The studies show some clear differences between age groups and gender. The paper has shown that technology impacts inclusion activity in technology dominated societies, although further research is needed. The paper argues that we may be seeing some structural changes in society along the structural lines traditionally associated with gender. As the paper argues, age may be the new gender. 


\section{References}

Adams, C., Avison, D., and Millard, P. "Personal Trust Space in Mobile Commerce," paper presented at the Sixth International Conference on Electronic Commerce Research (ICECR6), INFORMAT, Dallas, TX, October 23-26, 2003.

Adams, C., and Fitch, C. "Mobile Support for Community Healthcare: A Janus View," in E. Lawrence, B. Pernici, and J. Krogstie (eds.), Mobile Information Systems, New York: Springer 2004, pp. 341-349.

Adams, C., and Millard, P. "Personal Trust Space and Devices: 'Geography Will Not Be History' in the M-Commerce Future," paper presented at the Hawaii International Conference on Business (HICB), Honolulu, HI, June 18-21, 2003.

Britton, L., and Casebourne, J. "Defining Social Inclusion," Working Brief 136, Centre for Economic and Social Inclusion, n.d. (available online at http://www.cesi.org.uk/ docPool/defsocinc.pdf).

DoH. "Delivering the Plan," Department of Health, 2002 (available online at http://www.doh.gov.uk/).

Economist. "Computing's New Shape," The Economist, November 23, 2002, pp. 9-10, 85-87.

EOHCS. "Healthcare Systems in Eight Countries: Trends and Challenges," European Observatory on Health Care Systems, London School of Economics, 2002.

Fitch, C. J., and Adams, C. "Mobile Supported Patient Care: The Dichotomy of National and Local Needs," in I. Kushchu (ed.), Mobile Government: An Emerging Direction for eGovernment, Hershey, PA: Idea Group Publishing 2006 (forthcoming).

Hebert, M. A. "Impact of IT on Health Care Professional: Changes in Work and the Productivity Paradox," Health Services Management Research (11), 1998, pp. 69-79.

ICM. "Retail Week Survey," January 2002 (available online at http://www.sussex.ac.uk/ library//massobs/archive publications.html).

Jeffcote, R., Adams, C., and Su, Q. "Mobile Telephones: Just Another Gendered Technology?," paper presented at the IFIP8.2 OASIS Working Conference and SIG at the International Conference on Information Systems, Seattle, WA, December 14, 2003.

Levitas, R. "The Idea of Social Inclusion," paper presented at the Social Inclusion Research Conference, The Canadian Council on Social Development and Human Resources Development, Ottawa, March 27-28, 2003 (available online at http://www.ccsd.ca/events/inclusion/papers/rlevitas.htm).

Rantalaiho, L., and Heiskanen, T. (eds). Gender Practices in Working Life, London: Macmillan Press, 1997a.

Rantalaiho, L., and Heiskanen, T. "Persistence and Change of Gendered Practices," in L. Rantalaiho and T. Heiskanen (eds.), Gender Practices in Working Life, London: Macmillan Press, 1997b., pp 191-196.

Sheridan, D. "Damned Anecdotes and Confabulations: Mass-Observation as a Life History," Mass-Observation Archive Occasional Paper No. 7, University of Sussex Library, UK, 1996 (available at http://www.sussex.ac.uk/library//massobs/archive_publications.html).

Tannen, D. You Just Don 't Understand. Men and Women in Conversation, New York: William Morrow Publications, 1990.

Thomas, D. "M-commerce: A False Start?," Computer Weekly, January 16, 2003, p. 18.

Turkle, S. Life on the Screen: Identity in the Age of the Internet, New York: Simon and Schuster, 1995.

Wajcman, J. Feminism Confronts Technology, Cambridge, UK: Polity Press, 1991.

Wallace, P. The Psychology of the Internet, Cambridge, UK: Cambridge University Press, 1999.

Wanless, D. "Securing Our Future Health: Taking a Long-Term View-The Wanless Report," HM Treasury, 2002 (available online at http://www.hm-treasury.gov.uk/ Consultations_and_Legislation/wanless/consult_wanless_final.cfm?). 
Warschauer, M. Technology and Social Inclusion: Rethinking the Digital Divide, Cambridge, MA: MTT Press, 2003

Warschauer, M. "Reconceptualizing the Digital Divide," First Monday (7:7), July 2002 (available online at http://www.firstmonday.org/issues/issue 7_7/warschauer/).

\section{About the Authors}

Carl Adams is a principle lecturer at the University of Portsmouth. He has a Ph.D. in Information Systems development and an M.Sc. in Management Science, both from Southampton University, UK. His research interests are in Information Systems, mobile technologies and the impact of technology on society. He can be reached at carl.adams@port.ac.uk.

Tineke Fitch is a senior lecturer at the University of Portsmouth, with a Ph.D. in health informatics and telemedicine and an M.Sc. in Information Systems plus qualifications in business and human resource management. Prior to joining the University of Portsmouth, she held management positions in industry and the UK National Health Service. She is a senior member of the Centre for Healthcare Modelling and Informatics at the University's School of Computing and her research includes the use of telemedicine in elderly care and social aspects of e-health applications. She can be reached at tineke.fitch@port.ac.uk. 